\title{
Atividades argumentativas em livros didáticos de Física do PNLD 2015: o incentivo ainda é escasso
}

Argumentative activities in Physics textbooks of the PNLD 2015: the stimulus still scarce

\author{
André Henrique Silva Souza ${ }^{1}$ \\ Rodrigo Drumond Vieira ${ }^{2}$ \\ Viviane Florentino Melo $^{3}$
}

\section{Resumo}

Pesquisas em educação em ciências apontam que a argumentação é uma prática necessária para os processos ativos de aprendizagem dos estudantes. Os documentos oficiais têm sinalizado para a necessidade de incorporar práticas que dão suporte a processos argumentativos em sala de aula. Considerando que o livro didático tem sido muitas vezes utilizado pelos professores no ambiente escolar como um condutor do currículo, consideramos que ele pode (e deve) apresentar métodos para dar suporte aos processos argumentativos em sala de aula. Desta forma, neste trabalho analisamos se atividades de argumentação são estimuladas ou evocadas por atividades que o livro didático propõe. Analisamos sete das quatorze coleções aprovadas pelo PNLD (2015) para o caso do livro didático de Física para o Ensino Médio. Nossos critérios de análise se baseiam em como a estrutura da atividade é apresentada (bem ou mal estruturada) e se os marcadores "justificativas recíprocas" e "contraposição de ideias" estão sendo evocados ou utilizados. Os resultados indicam que os livros didáticos apresentam em parte, suporte para o processo argumentativo, mas esse suporte ainda é muito incipiente.

Palavras chave: argumentação; livro didático; educação em ciências.

\section{Abstract}

Research in science education has pointed that argumentation is a necessary practice for the students' active processes of learning. The official documents signal to the need of introducing support in the classroom for the development of argumentation. Since the science and physics text books have been used by teachers as a curriculum conductor in their classes, we consider that the physics text books can (and must) present methods and means for promoting and support argumentation in the classroom. In align with these assumptions, this study aims to analyze if argumentation processes are stimulated and evocated by activities of each analyzed textbook. We analyzed seven of the fourteen collections of the PNLD (2015) for the case of physics textbooks. Our analyses are based on

\footnotetext{
1 andrehsms@gmail.com

2 rodrumond@gmail.com

3 melovivi2211@hotmail.com
} 
three criteria: the structure of the proposed activity (well or ill-structured) and the markers "contrapositions of ideas" and "reciprocal justifications" The purpose of the analysis is to show if these criteria are evocated or used in the physics text books activities. The results show that the analyzed books present, partially, support for the argumentative processes.

Keywords: argumentation; textbook; science education.

\section{Introdução}

O processo de ensino e aprendizagem vem sendo impactado pelas mudanças econômicas, sociais, políticas e culturais, o que leva a uma reavaliação do papel da escola e dos professores na formação dos estudantes (LIBÂNEO, 1998). Nessa nova perspectiva, a escola deve preparar o cidadão quanto aos aspectos profissionais, científicos, culturais, éticos e morais, tornando-o apto a ter uma postura crítica frente a questões recorrentes da sociedade globalizada.

Visando desenvolver estas competências, o novo ensino médio brasileiro foi dividido em quatro grandes áreas do conhecimento (BRASIL, 2002): a área de Linguagens, Códigos e suas Tecnologias; a de Ciências da Natureza e suas Tecnologias; Ciências Humanas e suas Tecnologias; e Matemática e suas Tecnologias.

Nestas quatro grandes áreas são atribuídas competências que majoritariamente deverão ser estimuladas pelos educadores ao longo da vida escolar, não sendo elas exclusivistas, mas podendo encontrar suporte umas nas outras.

A área de Linguagens, Códigos e suas Tecnologias foca na representação e comunicação, já em Ciências Humanas e suas Tecnologias a contextualização sociocultural é o aspecto central, as Ciências da Natureza e suas Tecnologias visam os processos e produtos das ciências e Matemática e suas Tecnologias, engloba o raciocínio lógico.

Atualmente há um consenso quanto à necessidade de se adotar formas de ensino que visem um engajamento mais ativo e interativo por parte dos estudantes (KELLY, 2007, JIMENEZ-ALEIXANDRE \& ERDURAN, 2008). Sendo assim, os estudantes alcançam o aprendizado em um processo complexo, de elaboração pessoal e social, para o qual o professor e a escola contribuem, permitindo ao estudante se comunicar, situar-se em seu grupo, debater seus pontos de vista, aprender a respeitar e a fazer-se respeitar.

Os PCNEM (2002) indicam que os estudantes devem ter oportunidades de argumentar em sala de aula. No entanto, pesquisas apontam que professores e licenciados não sabem distinguir claramente uma argumentação de uma explicação, (AUTORES, 2013a; AUTORES, 2013b). Assim, é fundamental que existam critérios claros para os docentes sobre como diferenciar uma argumentação de uma explicação. No sentido de esclarecer esta questão vamos começar caracterizando a explicação.

De acordo com Bronckart (1999), quando nos situamos no campo da explicação, o objeto explicado apresenta-se como não controverso para os interlocutores. Geralmente há uma diferença de hierarquia em relação a quanto dominamos o assunto em questão, por exemplo, a relação tradicional entre professor e estudante. Nessa relação tradicional, o professor é o porta voz (e autoridade) legítima para explicar sem ser questionado.

Já a argumentação é compreendida, segundo Autores (2009), baseados em Billig (1996), como a evolução de contraposições e justificativas sobre algum assunto. Geralmente as pessoas que estão participando da argumentação, possuem um certo nível de conhecimento sobre o assunto (cf. CHARAUDEAU \& MAINGUENEAU, 2004). Dentro desta 
organização a todo momento podemos justificar uma afirmação de modo a persuadir o ouvinte, tendo em vista o contra argumento apresentado por ele (AUTORES, 2013a)

Essa perspectiva sobre a argumentação é particularmente problemática ao considerarmos os livros didáticos de Física. Segundo as disposições sobre o uso do livro didático dado pelo Programa Nacional do Livro Didático (PNLD) (BRASIL, 2014), é importante a participação do professor no processo de escolha do livro didático em função da realidade da escola e do estudante, já que o livro será um apoio as práticas pedagógicas adotadas, visando a melhoria no ensino.

Pesquisas da área têm apontado (CARDOSO \& ARAÚJO, 2012; CARNEIRO \& MÓL, 2005; GÜLLICH \& SILVA, 2013) que apesar dos avanços das ferramentas tecnológicas para o ensino, o livro didático ainda é muito utilizado como condutor do currículo e das práticas pedagógicas nas escolas. Deste modo o livro didático influencia largamente as aulas dos professores de Ciências no ensino médio, seja sob a forma de atualização, estruturação das aulas ou guia dos estudantes na compreensão do mundo exterior.

Dentro desta perspectiva, entendemos que o livro didático constitui um condutor escrito de escolhas curriculares, sendo assim um roteiro oficial para a escola e professores. Portanto, considerando a importância dos professores introduzirem argumentação em sala de aula, é importante compreender como a argumentação é (ou não é) construída nos textos dos livros didáticos e sob quais alicerces essa construção se apresenta.

Este é, precisamente, o objeto de investigação neste artigo: analisar, se os processos de argumentação são estimulados ou evocados por atividades que os livros didáticos de física propõem. Analisamos sete coleções do PNLD de física de 2015. Na seção seguinte vamos apresentar uma perspectiva sobre os livros didáticos e sobre argumentação que informa os procedimentos metodológicos e análises dos livros didáticos de física para ensino médio a que tivemos acesso.

\section{O livro didático e o PNLD de 2015}

O Guia do Programa do Livro Didático 2015 (PNLD 2015) é utilizado para análise de pré-requisitos que devem estar presentes nos livros didáticos. Os livros são selecionados seguindo critérios eliminatórios e classificatórios de forma periódica seguindo ciclos trienais. Em 2015, do total das 185 obras avaliadas, 99 foram aprovadas, sendo que neste ano também foram analisadas obras multimídia compostas de livros digitais.

Foram classificadas as obras que respeitaram a legislação, às diretrizes e as normas oficiais, relativas ao ensino médio (Constituição Brasileira; Estatuto da Criança e do Adolescente; Leis de Diretrizes e Bases da Educação Nacional 1996; Diretrizes Curriculares Nacionais para o Ensino Médio; Resoluções e Pareceres do Conselho Nacional de Educação) com observância de princípios éticos e democráticos necessários à construção da cidadania e ao convívio social.

A cada triênio, os editores corrigem e atualizam conceitos, informações e procedimentos experimentais presentes nas coleções anteriores, respeitando tanto os avanços e as conquistas acadêmico-científicas, quanto os princípios didáticos e pedagógicos pertinentes e adequados à natureza da coleção. Esta revisão é feita observando o parecer redigido pelos avaliadores do PNLD, visando melhor adequação ao plano e melhoria do material didático.

Tendo em vista essa perspectiva sobre os livros didáticos do PNLD, levantamos a seguinte questão: qual seria o papel do livro didático em promover argumentações em 
salas de aula? A literatura nacional tem avançado muito pouco nesse sentido, o que nos levou a indagar de uma forma mais ampla o que as pesquisas sobre livros didáticos nos dizem sobre os seus papéis e funções no ensino de ciências e física. Assim, na próxima seção vamos comentar e fazer uma breve revisão sobre as pesquisas acerca do livro didático.

\section{Pesquisa sobre livros didáticos}

O estudo do livro didático não é um campo recente de investigações, majoritariamente suas pesquisas versam sobre conteúdos visando a busca por concepções equivocadas (NAIRON; JÚNIOR \& MEDEIROS, 1998), analisando qual o cunho ideológico apresentam (DOMINGUINI, 2010), como está inserido o processo histórico no campo das ciências (VIDAL \& PORTO, 2012). As pesquisas também analisam se o livro didático utiliza alternativas diversas para auxiliar o processo de aprendizagem (MARINHO; OLIVEIRA \& FONSECA, 2012) e se cumpre com as determinações e políticas do Ministério da Educação (GARCIA, 2012).

Nesta perspectiva, um trabalho relevante é o de Neto e Fracalanza (2003) no qual os autores observaram o comportamento dos professores a respeito dos livros didáticos. Eles concluíram que os professores se sentem frustrados diante da impossibilidade de opinar sobre a reestruturação à medida que as obras são feitas, necessitando assim de várias fontes para montar o conteúdo programático.

Os editores na tentativa de montar um livro que se enquadra nas diretrizes estabelecidas pelo PNLD focam nas questões que são eliminatórias, todavia pouco ou nada fazem em relação aos itens classificatórios. A busca por essa elegibilidade diante do PNLD imprime um caráter de mercadoria ao livro didático, onde quem possui a melhor propaganda acaba conseguindo entrar no universo escolar.

Após uma extensiva busca na literatura (GARCIA, 2012; MARINHO et. al., 2012; FERREIRA \& SELLES, 2000; HÖFLING, 2000; SANJOSÉ, SOLAZ \& VIDAL-ABARCA, 1993;RIBEIRO \& MARTINS, 2007; CUNHA \& CALDAS, 2000; NETO \& FRANCALANZA, 2003;CARNEIRO \& MÓL, 2005; GÜLLICH \& SILVA, 2013; JUNIOR, LUNA \& LINHARES, 2014;MACEDO, 2004) a respeito das pesquisas desenvolvidas nos livros didáticos, percebemos que os assuntos mais encontrados estão ligados a forma como o conteúdo se apresenta, relação dos conceitos com a história e filosofia das ciências, experimentos que busquem elicitar do estudante conceitos prévios, identificação de erros conceituais nas leis e teorias e adequação as normas e exigências do PNLD.

Assim, a pesquisa sobre argumentação escolar precisa urgentemente considerar se e como os processos argumentativos são estimulados ou evocados pelo livro didático. Este trabalho vem precisamente cumprir o papel de estabelecer critérios para analisar o livro didático de física quanto ao estímulo à argumentação escolar ("se o livro estimula ou evoca processos argumentativos"). Os critérios que propomos são os seguintes: 1) Atividades bem ou mal estruturadas; 2) contraposição de ideias; 3) Justificativas recíprocas. Na próxima seção apresentamos o referencial teórico para a construção dessas categorias de análise. 


\section{Referencial teórico}

Segundo Cho e Jonassen (2002), estudantes que são expostos a atividades mal estruturadas produzem mais argumentos quando estão em busca de uma solução, do que estudantes engajados em atividades bem estruturadas. No caso das atividades mal estruturadas, os estudantes precisam levantar mais suposições para a produção e sustentação de respostas alternativas. Assim, sob essa perspectiva, atividades que possuem uma resposta única ou privilegiada contribuem menos para o processo de argumentação.

Autores (2009; 2013b), propõem dois marcadores que caracterizam uma argumentação: contraposição de ideias (opiniões) e justificativas recíprocas. Os autores mostram que características que dão suporte a argumentação são asseguradas pelos dois marcadores, são elas: persuasão, disputa, certo grau de simetria entre os interlocutores, verossimilhança das declarações, presença de mais de uma opinião e justificativa para as opiniões. As características se relacionam umas com as outras, desta forma, faremos umabreve síntese sobre cada uma delas a seguir.

\section{Características da argumentação}

A fim de detalhar essas características, tomaremos por base aquelas contemplados pelos marcadores na perspectiva de análise de Autores (2013).

\section{Persuasão}

A persuasão é garantida pelos dois marcadores, pois se justificamos uma opinião que está em contraposição com outra é porque desejamos que ela seja aceita. Só a justificativa não nos garante o convencimento, visto que ela já pode ser aceita e estaríamos apenas ampliando o conhecimento. Se somente há contraposição, isso não nos garante que as opiniões vissem o convencimento, já que, se não há suporte (justificativas) para uma opinião, racionalmente não podemos fazer uma escolha baseada na razão, pois não temos evidências racionais que nos levem a considerar uma opinião melhor que a outra.

\section{Disputa}

Essa característica é garantida pelo marcador "justificativas recíprocas", porque uma primeira opinião entra em concorrência com uma segunda à medida que são acrescentadas justificativas à primeira que a tornam melhor ou mais aceitável que sua concorrente. Podem ser acrescentadas novas opiniões à primeira o que leva a continuidade da argumentação. Esse processo contínuo de reconstrução das justificativas é chamado por Billig (1996) de a "busca pela última palavra". Desta forma o marcador "justificativas recíprocas" garante a possibilidade de continuidade da disputa (i.e. argumentação).

\section{Certo grau de simetria entre os interlocutores}

A simetria é garantida pelos dois marcadores, pois se justificamos uma opinião em contraposição com outra, é porque nos sentimos desafiados pela posição alheia. Se isso ocorre é porque consideramos que a opinião de outro é digna de ser considerada para finalidade de ponderação.

Se houvesse grande assimetria entre os interlocutores, a atitude seria de aceitar a declaração, pois é feita por um agente supostamente superior, considerando o domínio do 
conhecimento em jogo. Isso leva a uma orientação discursiva explicativa, que se estabelece quando um dos interlocutores tem posição de destaque. O marcador contraposição de ideias, garante que há certo grau de simetria entre os interlocutores, que ao contrapor-se mutuamente, estão, de fato, reconhecendo-se reciprocamente como "empoderados" para discutir e falar naquele contexto.

\section{Verossimilhança das declarações}

A verossimilhança das declarações é garantida pelos dois marcadores, pois declarações só se tornam opiniões se houver outras que a contradigam, e portanto, houver necessidade de justificá-las. Uma declaração considerada absoluta não pressupõe outras declarações que a contradigam. Logo, se há contraposição e justificativas recíprocas, há aavaliação de que as opiniões são verossimilhantes.

\section{Presença de mais de uma opinião}

O marcador "contraposição de ideias" garante que há mais de uma opinião em jogo: uma opinião só pode ser contraposta se existir, pelo menos, mais de uma opinião.

\section{Justificativas para as opiniões}

O marcador "justificativas recíprocas" garante que existem justificativas para as opiniões.

\section{Metodologia}

Neste trabalho analisamos uma amostragem dos livros de Física do ensino médio que foram selecionados pelo PNLD 2015, e buscamos avaliar se os livros apresentam suporte para o processo de argumentação. Para ter acesso às coleções entramos em contato com escolas estaduais em Niterói - RJ e das quatorze coleções aprovadas no PNLD2015, conseguimos acesso à sete.

Entramos em contato com professores conhecidos de escolas de outras cidades à procura das coleções que faltavam, e também buscamos estabelecer comunicação com as editoras, mas não conseguimos o restante das obras. A falta de acesso a todas as coleções foi um fator que limitou nossa amostragem a sete livros.

Para identificar as possíveis situações propostas que dão suporte à argumentação, o primeiro autor (que também chamaremos de "analista") identificou no sumário das coleções palavras ou frases chaves que poderiam fazer referência a atividades argumentativas, como exemplo: pense, saiba mais sobre, texto e interpretação, algo a mais, você sabe por que, atividade em grupo, investigar é preciso, debata e discuta.

Ao encontrar uma dessas palavras chave, o analista checou a página referenciada e leu a proposta apresentada buscando identificar se a atividade era mal estruturada (Cho \& Jonassen, 2002), o que poderia ser um incentivo ao processo argumentativo. Em seguida, o analista verificou se nos comandos das atividades existia a presença de um ou dois dos marcadores, "justificativas recíprocas" e "contraposição de ideias", de forma implícita ou explícita. Esses marcadores, conforme discutimos são necessários para o estabelecimento e desenvolvimento de argumentações. 
Ao término da análise do sumário, cada coleção foi folheada à procura de palavras chave no título das subseções, sugerindo que poderia ter um enfoque na argumentação. Em cada coleção escolhemos para apresentação neste trabalho um exemplo de cada tipo de boxe que poderia estimular o debate e fizemos uma síntese delas. A recorrência das atividades argumentativas não foi analisada devido à heterogeneidades desse tipo de atividades (boxes, pense e responda, etc). Na próxima seção apresentamos os resultados.

\section{Análise e resultados}

Utilizando o referencial teórico apresentado neste trabalho, analisamos as coleções de Física aprovadas no PNLD 2015 observando o suporte que apresentam ou não para a introdução de práticas argumentativas em sala de aula.

\section{- Coleção Física}

Autores: Bonjorno, Clinton, Eduardo Prado e Casemiro - Editora FTD.

A coleção Física da editora FTD, não apresentou na análise do sumário nenhuma das palavras chave que poderiam remeter à argumentação, apesar de conter boxes que fornecem ao estudante informações extras que contribuem para a compreensão do conteúdo, visto que associa o conteúdo com situações do cotidiano.

Fazendo a análise das subseções, encontramos boxes distribuídos aleatoriamente ao longo das unidades chamados "Pense e Responda", que tem por objetivo checar a compreensão que o estudante teve ao ser exposto ao conteúdo. O conteúdo dos boxes consiste em perguntas que estimulam o raciocínio e reflexão sobre os princípios apresentados.

As atividades propostas pelas seções da coleção não apresentam suporte para o processo de argumentação. Nos casos analisados, as perguntas são bem estruturadas levando a uma resposta objetiva. Como as respostas são objetivas, há pouco espaço para a produção de "contraposição de ideias" e "justificativas recíprocas". De fato, esses marcadores não foram encontrados nesta atividade tampouco no restante da coleção. Vale ressaltar que o volume dois desta coleção não apresenta a seção "Detalhes sobre", esta seção reaparece no volume três.

\section{- Coleção Física Interação e Tecnologia}

Autores: Aurélio Gonçalves Filho e Carlos Toscano - Editora Leya.

A coleção Física Interação e Tecnologia da editora Leya apresenta a seção "Texto e interpretação" no sumário e em todos os capítulos do livro. Esta seção aborda aspectos históricos, controvérsias científicas e o contexto social de produção do conhecimento. Ao final da seção, são propostas atividades que favorecem a compreensão dos principais tópicos abordados.

Como exemplo desse tipo de atividade, o capítulo seis do volume um, aborda o conteúdo de fluidos por meio de um texto sobre como atua a força de sustentação nas asas de um avião baseado no princípio de Bernoulli. Através de uma figura apresenta como é o comportamento das linhas de corrente que podem ser utilizadas como um medidor da densidade do fluido e utiliza uma aproximação em relação à maneira que um fluido age ao encontrar obstáculos e a água, sendo esta uma analogia de fácil visualização para o 
estudante. Usando esta analogia o texto descreve o comportamento da água ao passar por uma mangueira de jardim, detalhando o que acontece quando ocorre no entorno de um estrangulamento.

Após essa explicação, o livro sugere quatro questões a respeito do texto. As duas primeiras visam verificar se foi realizada a leitura, e a terceira, objetiva relembrar o conteúdo lido. E por fim, a quarta questão propõe um experimento para evidenciar empiricamente o princípio de Bernoulli:

Q4. Segure uma folha de papel pelas bordas na posição horizontal e assopre continuamente sobre ela durante alguns segundos. O que você observa? Como é possível explicar o que ocorre com a folha considerando a proposição de Bernoulli?

Nesta questão da seção, podemos perceber que a pergunta é bem estruturada, e a resposta é objetiva tendo como base o princípio de Bernoulli. O marcador "contraposição de ideias" também não é evidente neste caso. Na segunda parte da questão os estudantes precisam explicar o que ocorre com a folha. Essa explicação pode apoiar o marcador "justificativas recíprocas", onde os alunos irão sustentar o que observaram empiricamente utilizando o princípio de Bernoulli.

Quando passamos para a análise das subseções da coleção, não encontramos nenhuma atividade que poderia dar suporte para processos argumentativos.

\section{- Coleção Ser Protagonista}

Organizador: Angelo Stefanovits - Editora SM.

A coleção Ser Protagonista da editora SM apresenta boxes bem definidos e destacados abordando diferentes aspectos como fixação do conteúdo, expandindo o conhecimento e possíveis aplicações no cotidiano. Analisando o sumário, encontramos em alguns capítulos uma seção chamada "Física tem... (Geografia, História, Química, esporte)" que contém textos conectados à outras áreas do conhecimento ou aos aspectos da vida moderna. São textos provenientes de jornais, revistas e artigos onde os estudantes são expostos à outra linguagem e forma de pensar. $O$ intuito desta seção é o da interdisciplinaridade, para que o estudante reflita sobre o tema à luz de mais de uma área do conhecimento humano.

Por exemplo, no capítulo oito do volume três da coleção, a seção está relacionada ao tema de Geografia e aborda o fascínio pelos raios. É apresentado um apanhado histórico no Brasil onde existe o maior índice de raios por ano no mundo, especialmente no verão cerca de 60 milhões. É sugerido que isso pode estar associado à grande faixa territorial e a proximidade da linha do Equador.

Após a leitura do texto, os estudantes são convidados a responder perguntas que visam a compreensão do texto, são elas:

1. Quais fatores poderiam estar causando o aumento no número de raios no Brasil?

2. Com base no que você estudou, explique como se formam os raios em uma nuvem cúmulo-nimbo?

Podemos perceber que esta atividade é bem estruturada, já que orienta os estudantes a alcançar as respostas objetivas para as questões que constam no texto. Porém, ao pedir aos estudantes que expliquem com base no que eles estudaram, eles terão suporte no 
marcador "justificativas recíprocas". As justificativas que eles desenvolverem podem ser apoiadas pelas afirmativas apresentadas no texto e no conteúdo do capítulo.

Ao analisar as subseções do livro, encontramos um conjunto de boxes intitulado "Para refletir", que traz um texto com perguntas relacionadas ao tema abordado no capítulo. No volume um na página 209, há um boxe que apresenta o quadro "Noite estrelada sobre o Ródano", de Vicent van Gogh e um breve texto que afirma ser mais difícil observar o céu em áreas urbanas por causa do aumento da poluição e da presença de muita iluminação. Em seguida é feita a seguinte pergunta:

Nessas condições, como é possível para os astrônomos fazer observação do céu noturno e estudar o Universo?

Como o conhecimento de base disponível nesta etapa do "Para refletir" é o conhecimento prévio do aluno, nesse contexto a pergunta se apresenta como mal estruturada, permitindo que o estudante crie hipóteses pessoais para explicar como os astrônomos observam o universo. Ao elaborar hipóteses, o estudante poderá fazer uso do marcador "justificativas recíprocas" para sustentar as opiniões iniciais. Essa atividade pode possivelmente levar a uma contradição, visto que podem ser várias as opiniões levantadas e disto o potencial para gerar contradição - argumentação. Assim, nesta coleção identificamos os três marcadores para argumentação.

\section{- Coleção Física Ciência e Tecnologia}

Autores: Carlos Magno A. Torres, Nicolau Gilberto Ferraro, Paulo Antônio de Toledo Soares, Paulo César Martins Penteado - Editora Moderna.

A coleção Física Ciência e Tecnologia apresenta diferentes seções para o estímulo da argumentação e reflexão entre estudantes e professores no intuito de promover o aprofundamento e pensamento crítico do conteúdo relacionando-o com questões contemporâneas.

Ao analisar o sumário, a primeira seção que destacamos foi a "Atividade em grupo", que traz ao longo dos capítulos mais de um boxe de orientação. Por exemplo, na seção do volume um na página 13, o enunciado propõe que os estudantes façam entrevistas com pessoas idosas para descobrirem como era a vida delas em relação ao desenvolvimento tecnológico que possuíam, e uma descrição do que elas acompanharam ao longo da vida. Depois os estudantes devem debater como seria a vida sem o desenvolvimento tecnológico e traçar uma perspectiva de como será no futuro. Após estas tarefas os estudantes são convidados a desenvolver painéis e cartazes para mostrar o desenvolvimento de elementos tecnológicos citados nas entrevistas.

Ao debaterem sobre como seria a vida sem o desenvolvimento tecnológico, os estudantes estão diante de uma atividade mal estruturada, pois não há uma resposta objetiva. Por estarem apresentando as opiniões em grupo, o marcador "contraposição de ideias" é eminente, pois podem ocorrer discordâncias entre eles mantendo a discussão aberta. Já o marcador "justificativas recíprocas", pode ser amplamente utilizado na discussão para dar sustentação à opinião própria ou a de outro.

Já na seção "Você sabe por quê?", após a exposição de alguns conteúdos o livro traz perguntas para reflexão sobre situações que são observadas diariamente. A seção da página 236 do volume um traz a seguinte questão: 
Uma criança sentada em um balanço, mesmo sem tocar o solo, é capaz de, por si só, impulsionar-se e atingir grandes amplitudes. Você sabe explicar como isso é possível, de onde advém a energia que o balanço e a criança adquirem?

Consideramos que a pergunta se apresenta como mal estruturada dando margem para os estudantes divagarem em diversas opiniões (possibilidade de contraposição ideias), da mesma maneira que oferece suporte para o marcador "justificativas recíprocas" para manter o fundamento das opiniões apresentadas.

Ao realizar a análise das subseções da coleção não foi encontrada nenhuma que pudesse proporcionar suporte para o desenvolvimento de argumentação em sala de aula.

\section{- Coleção Física}

Autores: Guimarães, Piquera, Carron - Editora Ática.

Esta coleção apresenta duas seções distintas que conduzem a um pensamento mais elaborado acerca do conteúdo apresentado na unidade. Estas seções não foram localizadas durante a análise do sumário, mas sim observando as subseções da coleção. A seção "Física tem História" vai surgindo ao longo do desenrolar do livro como boxes que contém textos históricos relacionados com acontecimentos da época que os conceitos foram sendo apresentados à sociedade.

Na página 15 do volume três, o texto começa a relatar que na Grécia antiga, o âmbar, quando friccionado, adquiria propriedade de atrair pequenos objetos. Mas somente no século XVII começou a ser desenvolvido o estudo da eletricidade como ciência, com a descoberta da repulsão elétrica e a invenção do gerador de fricção.

O texto explica que outros cientistas se interessaram por esta área de estudo e ocorreram grandes contribuições e trabalhos no campo da eletricidade. Com o desenvolvimento da eletricidade surgiu uma melhor compreensão do eletromagnetismo que proporcionou a construção de diversas máquinas e motores revolucionando o modo de vida das pessoas.

Após a exposição desses fatos, o estudante então deve responder a seguinte questão: "Em sua opinião, quais as principais contribuições do eletromagnetismo à sociedade moderna?"

Consideramos que essa questão é mal estruturada, não objetiva, e por isso dá margem para o desenvolvimento das respostas. Nesse sentido, com o desenvolvimento da atividade, através da mediação da ação docente, existe a possibilidade de emergência dos outros dois marcadores "justificativas recíprocas" e "contraposição de ideias".

Nem todos os boxes da coleção contém atividade para o estudante refletir sobre o assunto, algumas delas apresentam apenas o texto relacionado com o conteúdo daquele capítulo relatando situações históricas ou curiosidades.

A seção "Compreendendo o mundo" aparece ao final de cada unidade do livro com o papel de unir diversos conhecimentos para explicar um fenômeno natural. Para isto, este boxe apresenta um texto que pode ser de revista, jornal, artigo ou de divulgação científica.

Por exemplo, na atividade das páginas 146 e 147 do volume três, é apresentado um texto que faz uma abordagem sobre a navegação e a bússola. O texto retrata um pouco sobre a história da bússola, que foi inventada na China, e que foi amplamente utilizada para a navegação no final do século XII. Com a revolução marítima, foi sendo aperfeiçoada e aliada a mapas para a criação de rotas marítimas que cruzavam o globo. 
Ao debaterem a respeito da afirmação do texto, os estudantes estão diante de uma atividade mal estruturada, pois é solicitado que eles discutam a afirmação. Ao apresentarem suas opiniões, o marcador "contraposição de ideias" pode surgir, pois pode haver discordâncias entre eles mantendo a discussão aberta. Já o marcador "justificativas recíprocas", também pode ser utilizado na discussão para dar sustentação à opinião própria ou à opinião de outro.

\section{- Coleção Conexões com a Física}

Autores: Glória Martini, Walter Spinelli, Hugo Carneiro Reis, Blaidi Sant'anna - Editora Moderna.

Esta coleção apresenta dois boxes distintos que propõem atividades que irão exigir a análise, compreensão e discussão dos desafios apresentados. Estas atividades foram identificadas realizando a análise do sumário. As atividades intituladas "Investigar é preciso" possuem experimento proposto com material de fácil aquisição e simples montagem. 0 foco central desta atividade é demonstrar a validade de um princípio físico.

Por exemplo, na atividade da unidade um, do volume um, na página 65, é proposta a construção de uma rampa com cabos de vassoura, tijolo, bolinha, trena, cronômetro e fita adesiva para estudo do deslocamento no Movimento Retilíneo Uniformemente Variado (MRUV).

O livro propõe a construção da rampa com os cabos de vassouras, marcação de distâncias proporcionais a quadrados inteiros apoiado em um tijolo. A bolinha deve ser liberada do topo da rampa cronometrando o tempo de descida e o instante em que passa nas marcações. Isto deve ser repetido pelo menos por duas vezes para confirmação dos dados e as informações devem ser expressas em um gráfico da posição pelo tempo.

Feito isso, deve-se responder as questões propostas que envolvem a análise direta dos dados coletados e do gráfico criado e outras que permitem uma abordagem mais dedutiva, pois neste caso, pretendem determinar a aceleração da bolinha durante a descida e análise da função horária do movimento. Uma sugestão do livro é utilizar uma câmera para filmar o movimento, deste modo com um editor de imagens pode-se encontrar os intervalos de tempo com mais precisão. Feito isso, é possível comparar os resultados para análise do erro nas medidas.

Neste boxe a atividade é bem estruturada requerendo respostas assertivas, não dando suporte para a argumentação. Os marcadores "contraposição de ideias" e "justificativas recíprocas" não possuem espaço para serem trabalhados. Neste caso, avaliamos que o suporte para a argumentação é frágil.

No boxe "Para pesquisar em grupo", temos um texto que discorre sobre algum tema relacionado à unidade estudada. No volume dois, unidade cinco, na página 262 da coleção, o tema abordado é o de Lentes esféricas, instrumentos ópticos e visão. Nesta seção o texto escolhido questiona se ler no escuro faz mal à visão. Uma opinião comum é que isso prejudica a visão, podendo ocorrer prematuramente a presbiopia, ou vista cansada. O livro propõe então que se faça uma pesquisa para descobrir se isso é verdade.

A pesquisa é organizada em fases de forma que se possa chegar a uma resposta contundente. Primeiro os estudantes são levados a perguntar para os familiares a opinião deles a respeito desse fato e anotar os diferentes pontos de vista e justificativas. Depois, devem pesquisar como funciona o mecanismo do olho. Em seguida, pesquisar quais são os 
sintomas que a leitura no escuro pode provocar e discutir qual a relação entre a falta de luze os defeitos da visão estudados na unidade.

Por fim, os estudantes devem realizar um teste com amigos para ver se alguém apresenta presbiopia. Para isso deve-se levar em conta que um adolescente sem problemas de visão deve conseguir ler um texto que esteja, no máximo, a $12 \mathrm{~cm}$ de distância. Na faixados 30 anos de idade, $20 \mathrm{~cm}$ do texto. E acima dos 40 anos, igual ou maior que $40 \mathrm{~cm}$ de distância. À medida que realiza o teste, os estudantes são solicitados a criar uma tabela com os resultados.

Neste boxe novamente, as questões são bem estruturadas com respostas objetivas as proposições feitas. Não obstante, o estudante depois de recolher as opiniões de seus familiares e analisar os diferentes pontos de vistas, tem acesso a uma polissemia, que pode relacionar-se com o marcador "contraposição de ideias".

Ao analisar as subseções da coleção, encontramos uma chamada "Demonstrar, discutir" aparecendo aleatoriamente. Por exemplo, o boxe no volume três, na página 89, apresenta imagens de medidores de energia elétrica residencial e apresenta um pequeno texto informando que os funcionários das companhias fornecedoras de energia elétrica fazem a leitura do consumo de energia para emitir a conta de luz.

Mesmo contendo no título da seção uma palavra chave, "discutir", em nenhum dos boxes desta atividade o estudante é estimulado a pensar e refletir sobre algum tipo de informação ou mesmo sobre o conteúdo apresentado através de questionamentos. Destaforma nenhum dos marcadores são evocados.

\section{- Coleção Física}

Autores: Alisson Ramos Artuso, Marlon Wrublewski - Editora Positivo.

Analisando o sumário da coleção, identificamos a presença de um boxe chamado "Investigação científica", que não apresenta uma frequência contínua ao longo das unidades. Ora aparece apenas um para o capítulo, ora temos dois ou mais boxes presentes. Ele apresenta experimentos de fácil realização, ou alguma questão social que pode ser analisada à luz de conceitos físicos e, ao final, propõe uma tarefa para refletir e discutir.

Por exemplo, o capítulo quatro do volume dois da coleção aborda o tema Estudo dos gases. O boxe "Investigação científica", na página 93, propõe um experimento com bexigas para que os estudantes percebam a variação no volume inicial. Este experimento é recomendado para ser realizado em dupla.

Depois de formularem as hipóteses, os estudantes devem começar a realizar o experimento proposto. Primeiro irão encher duas bexigas, sendo que uma delas deve ter o dobro do volume da outra. Então colocarão as bexigas em contato através de um tubo ou uma mangueira e irão observar o que vai acontecer. Se necessário, eles devem repetir a experiência para melhor observação. Então devem debater com seus colegas o que foi observado no experimento e explicar o que aconteceu. Depois devem avaliar as hipóteses iniciais diante do observado.

Este boxe pode desenvolver processos argumentativos, pois apresenta uma questão estruturada num formato de "pense sobre e depois verifique experimentalmente", o que, pode levar os participantes a criar hipóteses e sustentar cada uma delas. Isso pode evocar os marcadores "contraposição de ideias" e "justificativas recíprocas". 
Ao fazer a análise das subseções, não encontramos nenhum boxe que poderia permitir o desenvolvimento do processo argumentativo. A seguir apresentamos no quadro 1, uma síntese da análise completa realizada nas sete coleções.

Quadro 1 - Síntese dos resultados

\begin{tabular}{|c|c|c|c|c|c|c|}
\hline Coleção & Publisher & Analysis & Section & $\begin{array}{l}\text { Atividade mal } \\
\text { estruturada }\end{array}$ & $\begin{array}{l}\text { Contraposição } \\
\text { de ideias }\end{array}$ & $\begin{array}{l}\text { Justificativas } \\
\text { recíprocas }\end{array}$ \\
\hline \multirow{2}{*}{ Física } & \multirow{2}{*}{ FTD } & Subseção & Pense e responda & & & \\
\hline & & Subseção & Detalhes sobre & & & \\
\hline $\begin{array}{l}\text { Física, } \\
\text { interação e } \\
\text { tecnologia }\end{array}$ & Leya & Sumário & $\begin{array}{l}\text { Textos e } \\
\text { interpretações }\end{array}$ & & & $x$ \\
\hline \multirow{2}{*}{$\begin{array}{l}\text { Ser } \\
\text { Protagonista }\end{array}$} & \multirow{2}{*}{ SM } & Sumário & Física tem... & & & $x$ \\
\hline & & Subseção & Para refletir & $x$ & $x$ & $x$ \\
\hline \multirow{2}{*}{$\begin{array}{l}\text { Física, } \\
\text { Ciência e } \\
\text { Tecnologia }\end{array}$} & \multirow[t]{2}{*}{ Moderna } & Sumário & $\begin{array}{l}\text { Atividade em } \\
\text { grupo }\end{array}$ & $x$ & $x$ & $x$ \\
\hline & & Sumário & Você sabe porquê & $x$ & $x$ & $x$ \\
\hline \multirow[b]{2}{*}{ Física } & \multirow[b]{2}{*}{ Ática } & Subseções & Física tem história & $x$ & $x$ & $x$ \\
\hline & & Subseções & $\begin{array}{l}\text { Compreendendo o } \\
\text { mundo }\end{array}$ & $x$ & $x$ & $x$ \\
\hline \multirow{3}{*}{$\begin{array}{l}\text { Conexões } \\
\text { com a física }\end{array}$} & \multirow{3}{*}{ Moderna } & Sumário & Investigar é preciso & & & \\
\hline & & Sumário & $\begin{array}{l}\text { Para pesquisar em } \\
\text { grupo }\end{array}$ & & $x$ & \\
\hline & & Subseções & $\begin{array}{l}\text { Demonstrar, } \\
\text { discutir }\end{array}$ & & & \\
\hline Física & Positivo & Sumário & $\begin{array}{l}\text { Investigações } \\
\text { científicas }\end{array}$ & & $x$ & $x$ \\
\hline
\end{tabular}




\section{Conclusões}

A argumentação pode encontrar suporte nos livros didáticos, que podem oferecer meios que estimulem o desenvolvimento desta importante habilidade nos estudantes. 0 livro didático muitas vezes atua como um orientador do currículo para os professores e fonte quase única de pesquisa para os estudantes, sendo um instrumento muito presente no espaço escolar.

Desta maneira o livro didático pode apresentar atividades e recursos de maneira clara, que possibilitem o estímulo à argumentação no espaço escolar. Cho \& Jonassen (2002) encontraram resultados que sugerem que atividades mal estruturadas estimulam a ocorrência de argumentações.

Por meio de nossa pesquisa verificamos que as questões mal estruturadas foram pouco apresentadas e exploradas, sendo que encontramos majoritariamente questões objetivas no conjunto da amostra. Assim, as atividades mal estruturadas têm pouca representatividade na amostra analisada.

Este trabalho é um recorte do retrato de como a argumentação é inserida nos livros didáticos de Física. Os resultados indicam que nem todas as coleções apresentam suporte claro para a argumentação nos boxes. Ao analisar os enunciados das tarefas, encontramos poucas instruções e sugestões que ajudem o professor a gerar e gerir situações argumentativas. Nas atividades analisadas, em geral por se tratar de atividades individuais, 0 marcador "contraposição de ideias" é pobremente explorado. O marcador "justificativas recíprocas" foi utilizado mais vezes.

Portanto, concluímos que os livros analisados contribuem pouco para o estímulo à argumentação em sala de aula. Essa é uma realidade que precisa urgentemente ser transformada. Nesse sentido, consideramos que os critérios utilizados na análise dos livros (atividades mal estruturadas; contraposição de ideias; justificativas recíprocas) podem ajudar a superar essa lacuna, e contribuir para o avanço da pesquisa e para a produção de livros didáticos consistentes com a demanda educacional contemporânea. 


\section{Referências}

BILLIG, M. Arguing and thinking: a rhetorical approach to social psychology. Cambridge: Cambridge University Press, 1996.

BRASIL. Guia de livros didáticos: PNLD 2015: Física: Ensino Médio. Brasília: Ministério da Educação, 2014.

BRASIL. Parâmetros Curriculares Nacionais ( $\mathrm{PCN}+)$ Ensino Médio: orientações educacionais complementares aos Parâmetros Curriculares Nacionais - Ciências da Natureza, Matemática e suas Tecnologias. Brasília: MEC/Semtec, 2002.

BRONCKART, J. P. Atividade de linguagem, textos e discursos: por um interacionismo sócio discursivo. São Paulo: EDUC, 1999.

CARDOSO, L. D. R. \& ARAÚJO, M. I. O. Currículo de ciências: professores e escolas do campo. Ensaio - Pesquisa em educação e ciências, 14 (2), 121-135, 2012.

CARNEIRO, M. H. S. \& MÓL, W. L. P. S. G. S. Livro didático inovador e professores: uma tensão a ser vencida. Ensaio - Pesquisa em educação e ciências, 7(2), 1-13, 2005.

CHARAUDEAU, P.\& MAINGENEAU, D. Dicionário de análise do discurso. São Paulo: Contexto, 2004.

CHO, K.-L., \& JONASSEN, D. H. The effects of argumentation scaffolds on Argumentation and problem solving. Educational Technology Research and Development, 50(3), 5-22, 2002.

CUNHA, A. L. \& CALDAS, H.M.S.C.C.P. Sentido das forças de atrito e os livros de $8^{a}$ série. Caderno Brasileiro de Ensino de Física, 17(1), 7-21, 2000.

DOMINGUINI, L. O Conteúdo Física Moderna nos livros didáticos do PNLEM. Dissertação de Mestrado. Programa de Pós-Graduação em educação da Universidade do Extremo Sul Catarinense (PPGEUNESC). Criciúma, 2010.

FERREIRA, M.S. \& SELLES, S.E. A produção acadêmica brasileira sobre livros didáticos em ciências: uma análise em periódicos nacionais. Anais do IV ENPEC, 2000.

GARCIA, N.M.D. Livro didático de Física e de Ciências: contribuições das pesquisas para a transformação do ensino. Educar em Revista, 44, abril-jun, 145-163, 2012.

GÜLLICH, R.I.C. \& SILVA, L.H.A. O enredo da experimentação no livro didático: construção de conhecimentos ou reprodução de teorias e verdades científicas? Ensaio - Pesquisa em educação e ciências, 15 (2), 155-167, 2013.

HÖFLING, E. M. Notas para discussão quanto à implementação de programas de governo: em foco o Programa Nacional do Livro Didático. Educação e Sociedade, 21(70), 159-188, 2000.

JIMENEZ-ALEIXANDRE, M. P., \& ERDURAN, S. Argumentation in science education: an overview. In S. Erduran\& M. P. Jimenez-Aleixandre (Eds.), Argumentation in Science education: Recent developments and future directions (pp. 3-27). Dordrecht: Springer, 2008. 
JUNIOR, E.R; LUNA, F.J. \& LINHARES, M.P. Critérios para a avaliação de materiais didáticos impressos de História da Ciência para a Educação a Distância. Caderno Brasileiro de Ensino de Física, 31(2), 429-462, 2014.

KELLY, G. J. Discourse in science classrooms. In S. Abell \& N. Lederman (Eds.). Handbook of research on science education (pp. 443-470).Mahwah, NJ: Lawrence Erlbaum Associates, 2007.

LIBÂNEO, J; Adeus professor, adeus professora?: novas exigências educacionais e profissão docente. São Paulo: Cortes, 1998.

MACEDO, E. A imagem da ciência: foleando um livro didático. Educação e Sociedade, 25, 103-129, 2004.

MARINHO, A. B.; OLIVEIRA, M. C. \& FONSECA, F. S. R. Análise dos experimentos no livro didático de ciências: possibilidades e limites. Associação Brasileira de Ensino de Biologia SBEnBio, 1-7, 2012.

NAIRON, F.; JÚNIOR, M. \& MEDEIROS, A. Distorções conceituais dos atributos do som presentes nas sínteses dos textos didáticos: aspectos físicos e fisiológicos. Ciência \& Educação, 5(2), 1-14, 1998.

NETO, J. M. \& FRACALANZA, H. O livro didático de ciências: problemas e soluções. Ciência \& Educação, 9(2), 147-157, 2003.

RIBEIRO, R. M. L. \& MARTINS, I.O potencial das narrativas como recurso para o ensino de ciências: uma análise em livros didáticos de Física. Ciência \& Educação (Bauru), 13(3), 293309, 2007.

SANJOSÉ, V., SOLAZ, J.J. \& VIDAL-ABARCA, E. Mejorando La efectividad instrucional del texto educativo em ciencias: primeros resultados. Enseñanza de las Ciências, 11(2), 137-148, 1993.

VIDAL, P. H. O. \& PORTO, P. A. A história da ciência nos livros didáticos de química do PNLEM 2007. Ciência \& Educação, 18(2), 291-308, 2012.

VIEIRA, R. D.; NASCIMENTO, S. S. . Abordagem comunicativa, argumentação e objetivos didáticos: um episódio de sala de aual gerenciado por um estagiário. Educação em Revista (Online), v. 29, p. 15-36, 2013b.

VIEIRA, R. D.; NASCIMENTO, S. S. Uma proposta de critérios marcadores para identificação de situações argumentativas em salas de aula de ciências. Caderno Brasileiro de Ensino de Física, v. 26, p. 81-102, 2009.

VIEIRA, R.D.; NASCIMENTO, S. S. Argumentação no ensino de ciências: tendências, práticas e metodologia de análise. Curitiba: Appris, 2013a, 113p. 